\title{
Intracardiac polymethylmethacrylate cement embolism
}

Gabe Weininger, BS, Rajesh B. Sekar, MD, PhD, and John A. Elefteriades, MD, PhD (hon), New Haven, Conn

From the Aortic Institute at Yale University School of Medicine, New Haven, Conn.

Disclosures: J.A.E.: Principal, CoolSpine, Data and Safety Monitoring Board Terumo, Consultant, CryoLife. All other authors reported no conflicts of interest.

The Journal policy requires editors and reviewers to disclose conflicts of interest and to decline handling or reviewing manuscripts for which they may have a conflict of interest. The editors and reviewers of this article have no conflicts of interest.

Received for publication June 16, 2021; accepted for publication Sept 2, 2021; available ahead of print Oct 22, 2021.

Address for reprints: John A. Elefteriades, MD, PhD (hon), Aortic Institute at Yale New Haven, 789 Howard Ave, New Haven, CT 06519 (E-mail: john.elefteriades@yale.edu).

JTCVS Techniques 2021;10:358-60

2666-2507

Copyright (C 2021 The Author(s). Published by Elsevier Inc. on behalf of The American Association for Thoracic

Surgery. This is an open access article under the CC BY-NC-ND license (http://creativecommons.org/licenses/bync-nd/4.0/).

https://doi.org/10.1016/j.xjtc.2021.09.001

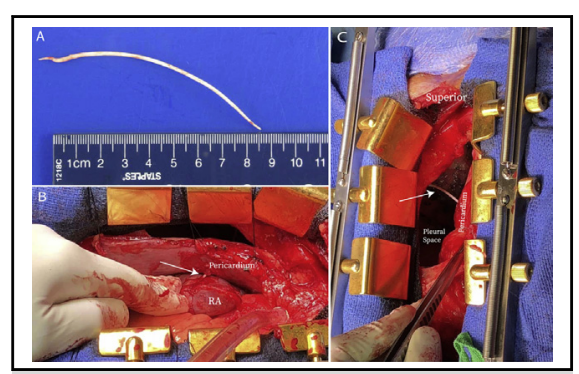

An intracardiac bone cement embolism formed 1 week after a vertebral kyphoplasty.

\section{CENTRAL MESSAGE}

These images were captured

from a recent case in which a

patient developed an intracar-

diac methacrylate cement em-

bolism 1 week after a vertebral

kyphoplasty.

See Commentary on page 361 . phoplasty for a mild-moderate compression fracture presented to the emergency department with dyspnea and right-sided chest pain that significantly worsened with movement. Chest $\mathrm{x}$-ray and computed tomography scan demonstrated a possible intracardiac foreign body for which the patient was taken to surgery (Figure 1). The patient underwent a median sternotomy that immediately revealed a $10.1 \times 0.2-\mathrm{cm}$ foreign body (Figure 2, A) perforating the right atrium (Figure 2, $B$ ), transgressing the pericardium into the pleural space (Figure 2,C), and puncturing the lung. The foreign body was extremely sharp and consistent with a polymethylmethacrylate (PMMA) bone cement embolism from his kyphoplasty 1 week previously (Video 1). Intracardiac cement embolism is a documented complication of kyphoplasty, in which PMMA can leak into the venous system and harden into a permanent embolus. ${ }^{1,2}$
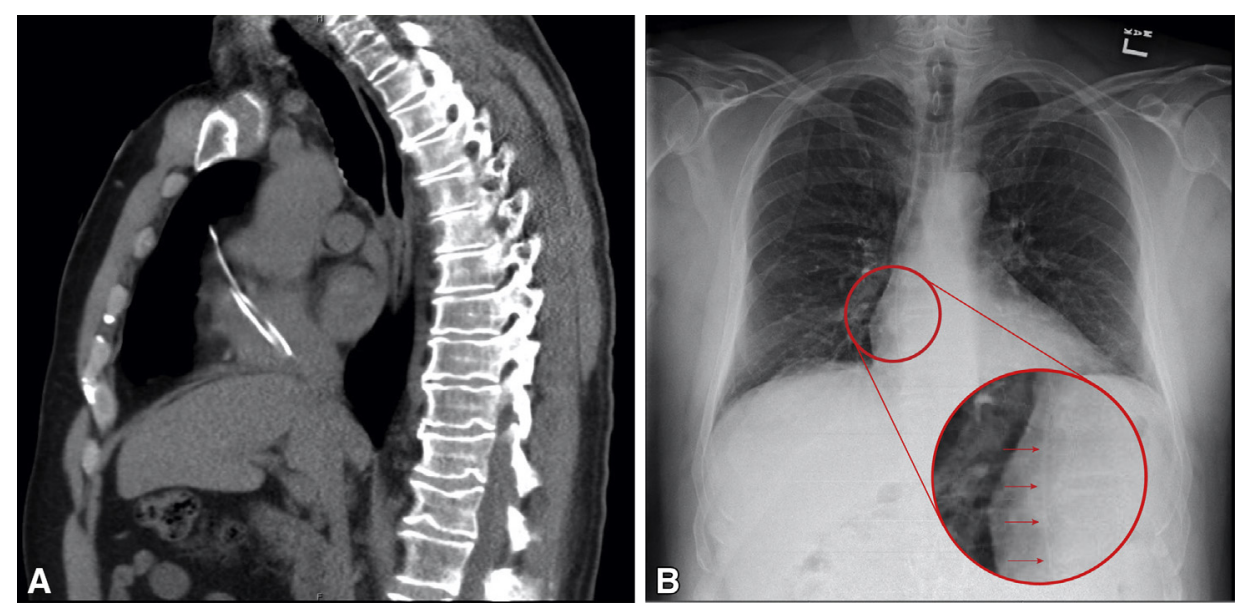

FIGURE 1. Intracardiac cement embolism on a chest computed tomography scan (A) and chest $\mathrm{x}$-ray (B) obtained when the patient presented to emergency department. 

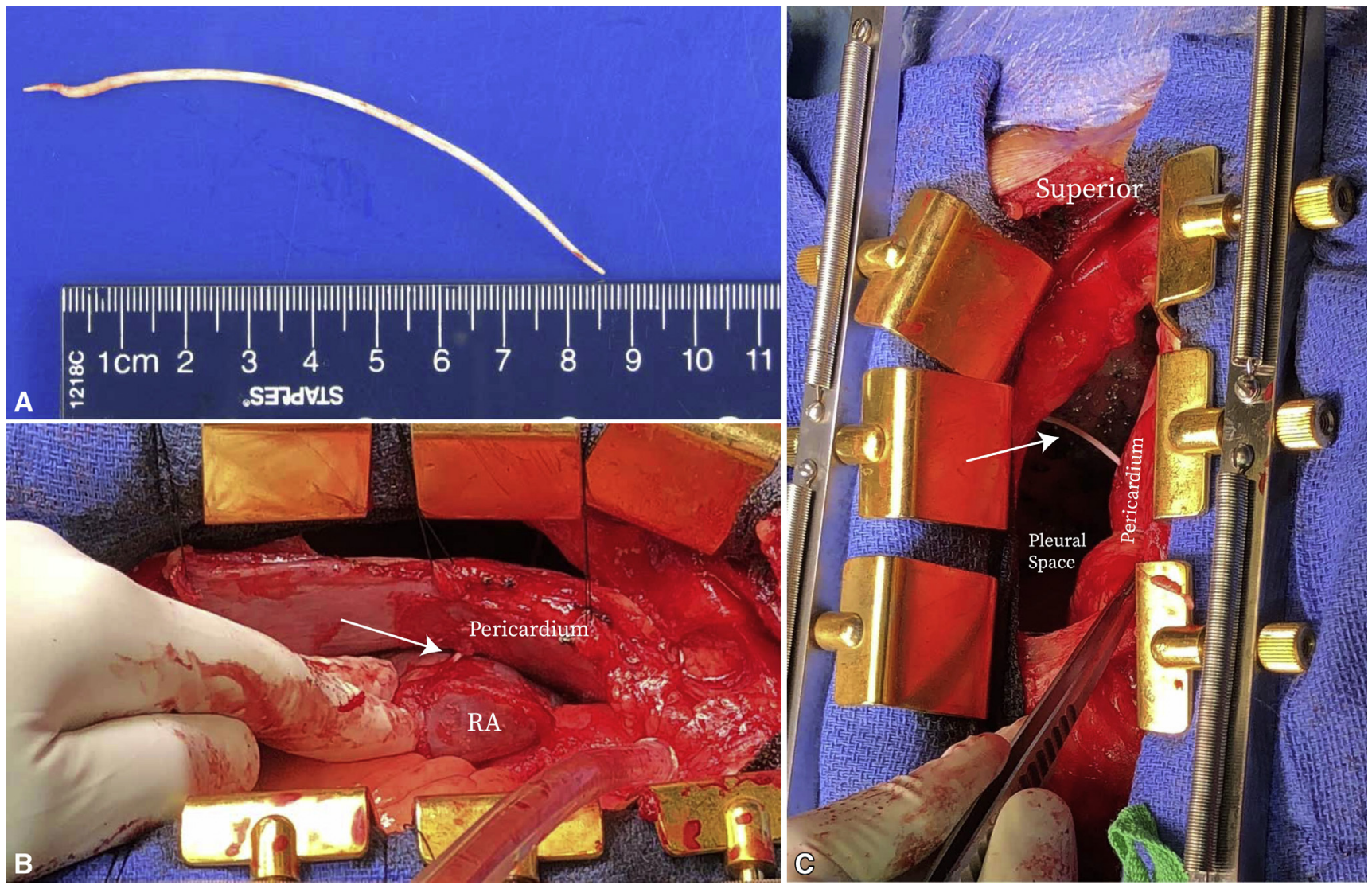

FIGURE 2. A long PMMA bone cement embolism that was removed from the patient's heart (A), perforating the right atrium before removal (B) and extending into the pleural space to puncture the lung (C). $R A$, Right atrium.

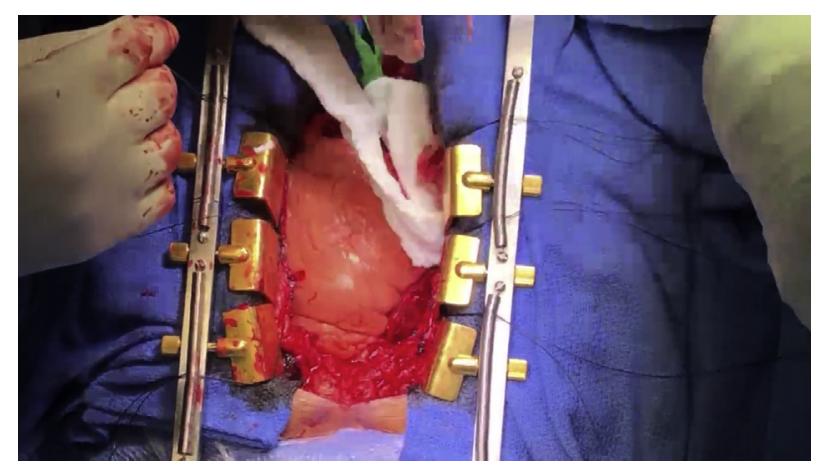

VIDEO 1. The removal of the long PMMA bone cement embolism from the patient's right atrium. Video available at: https://www.jtcvs.org/article/ S2666-2507(21)00603-9/fulltext.
This likely requires the cement be injected directly into a vein lumen or in close proximity to significant vein injury. Given the location of L5 kyphoplasty in this patient, we hypothesize that the cement was likely injected in a segment of the ascending lumbar vein, hemiazygos vein, or the vena cava itself (Figure 3). Fortunately, in this patient, the PMMA cement embolism was safely removed, and the right atrium was repaired without complication. This case and the accompanying images highlight the importance of having high clinical suspicion for cement embolism after kyphoplasty. Despite prior reports, ${ }^{1,2}$ including that by Park and colleagues, ${ }^{2}$ this potential complication of kyphoplasty needs to be more widely disseminated. The patient's informed consent was obtained for this article and use of the accompanying images. 


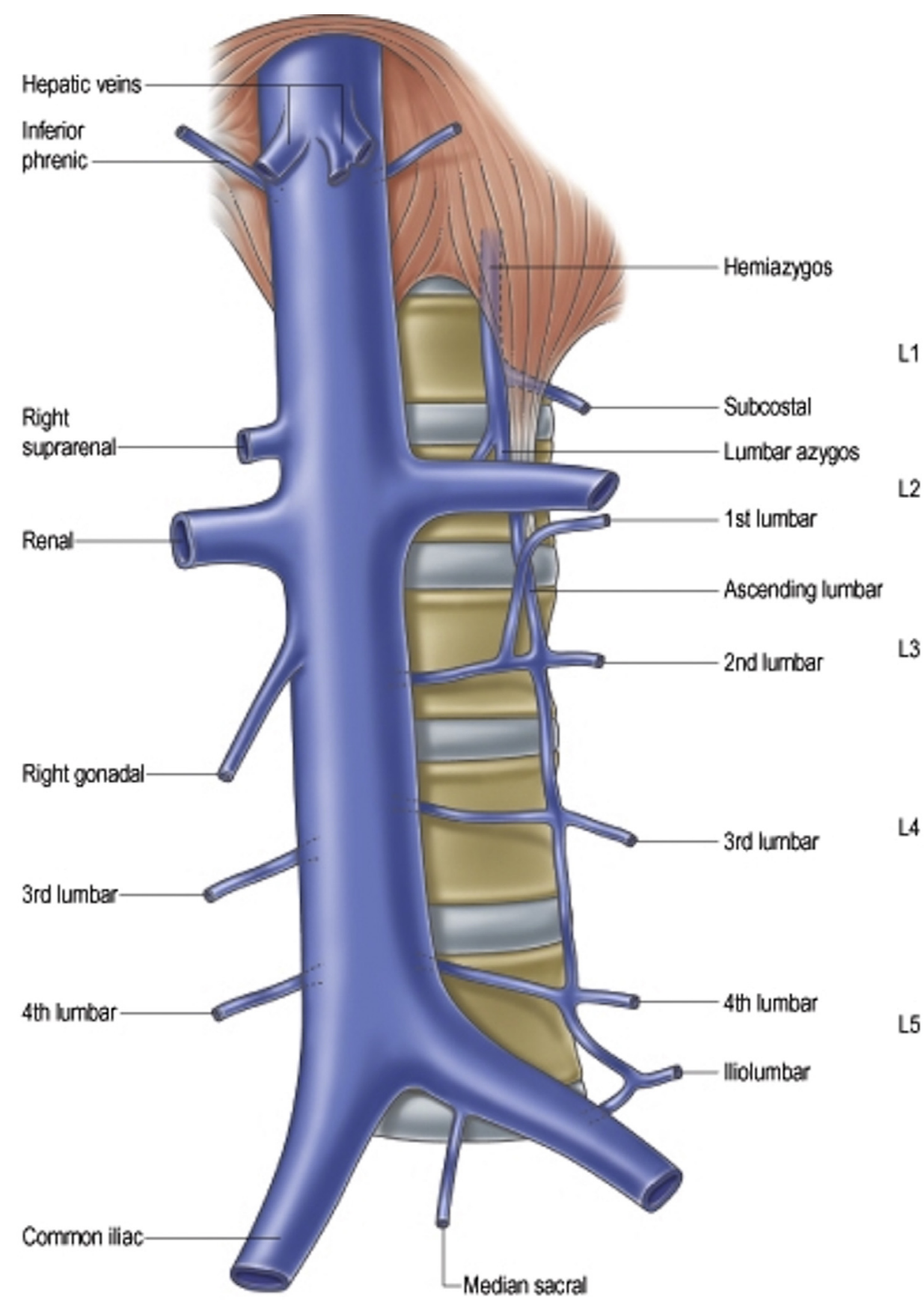

FIGURE 3. The local venous anatomy of the lower spine. Note the potential vulnerability of the lumbar veins, as well as the hemiazygous vein and the vena cava itself. Reproduced with permission from Alkahtani AA, Subahi A, Alaqla N, Algahtani HA. The "fisherman's waders" sign on bone scan: a case report. Br J Med Res. 2016;11:1-6.

\section{References}

1. Shridhar P, Chen Y, Khalil R, Plakseychuk A, Cho SK, Tillman B, et al. A review of PMMA bone cement and intra-cardiac embolism. Materials (Basel). 2016;9:821.
2. Park J-H, Choo SJ, Park S-W. Acute pericarditis caused by acrylic bone cement after percutaneous vertebroplasty. Circulation. 2005;111:e98. 